\title{
JUAN MARTÍN FERNÁNDEZ. APROXIMACIÓN AL PENSAMIENTO DE ALASDAIR MACINTYRE. BUENOS AIRES, EDITORIAL LOGOS, COLECCIÓN ESTUDIO, 2018, 112 PÁGINAS. ISBN Noo: 978-987-732-129-6.
}

\author{
Gerardo Rodríguez \\ (Universidad Nacional de Mar del Plata; \\ Consejo Nacional de Investigaciones Científicas y Técnicas) \\ gefarodriguez@gmail.com
}

Recibido: 30/11/2019

Aprobado: 19/12/2019

Juan Martín Fernández es Licenciado en Ciencia Política por la Universidad de Buenos Aires y Doctor, en la misma disciplina, por la Universidad de Granada. Su tesis, defendida en el año 2010, versa sobre La imprescindible complementariedad entre la ética y la política en el pensamiento de Alasdair MacIntyre. En 2017 publica Persona y Comunidad - Una Propuesta desde Alasdair MacIntyre, editorial Logos, obra destinada a explicarnos que tanto el desarrollo personal como el desarrollo comunitario implican una determinada propuesta ética-política: la ética de las virtudes y la política de las comunidades locales.

El libro que reseñamos está divido en una introducción, cinco partes que dan cuenta de su biografía intelectual, los temas centrales de su pensamiento, los elementos constitutivos de su forma de investigación y un resumen conclusivo, así como dos bibliografías completas referidas a las obras del autor y sus principales estudios.

Alasdair Chalmers MacIntyre es un intelectual profundo y complejo. Profundo, por la vastedad de su conocimiento; complejo, porque sus inquietudes académicas y personales lo llevaron siempre a una tensión constante entre los tiempos actuales y sus múltiples pasados.

Una de las primeras impresiones que suele tener cualquier lector que se aproxime a sus obras, es la percepción de su vasta erudición: la investigación interdisciplinar (en los ámbitos de la filosofía, la historia, la sociología, la política, la literatura, la psicología), el tránsito por diversas corrientes de pensamiento (marxismo, filosofía analítica, aristotelismo y tomismo) y el conocimiento profundo de una amplia gama de pensadores (Platón, Aristóteles, Sófocles, Tomás de Aquino, Diderot, Hume, Smith, Betham, Kant, Marx, Engels, Mill, Vico, Nietzsche, Collinwood, Freud, Kuhn, Popper, Taylor, Sandel, Walzer, Lukács, Rawls, Nozick, Skinner, Rorty, Arendt, Anscombe, Stein, Foucault, Hart, Dworkin, Ackerman), los cuales conformaron la cultura a la que hacemos referencia.

De esta forma, para él los postulados filosóficos, las creencias religiosas, las cuestiones morales o cuestiones jurídicas, no conforman verdades absolutas e inmóviles, sino todo lo contrario: se renuevan y revelan de utilidad según cada momento interpretativo, según cada etapa de su trayectoria intelectual; dicha trayectoria podría caracterizarse como de una hermenéutica constante, de allí que Juan Martín Fernández haya considerado acercarse a su pensamiento a partir de su biografía personal e intelectual. 
La apertura intelectual que caracteriza a MacIntyre le permitió relacionarse con diversas corrientes de pensamiento y con distintos autores de su tiempo. Con ellos dialogó críticamente a lo largo de su extensa carrera académica y sobre dicha base implementó una metodología caracterizada por el dinamismo en la búsqueda de la verdad y del bien dentro de un contexto histórico, también cabe la posibilidad de denominar esa metodología como "histórico-narrativa" o, simplemente, filosofía narrativa. Si bien la metodología narrativa posee una clara orientación en orden a la búsqueda de la verdad, existe la posibilidad de una crisis en orden a los criterios de verdad que se habían estipulado y, en esos casos, será necesario reformular los criterios que se tenían y establecer una nueva narrativa.

Nacido el 12 de enero de 1929 en Glasgow, Escocia (de padres presbiterianos), se aleja de la fe cristiana hasta que se reencuentra con ella siendo un hombre maduro, se acerca al marxismo por influencia de sus profesores de la Universidad de Manchester.

Lo anterior es esencial para comprender su pensamiento, dado que en tres de sus obras (1953, 1968, 1995) reflexiona sobre qué implica ser marxista y ser cristiano, las relaciones entre el marxismo y el cristianismo, y si se puede ser ambas cosas a la vez. En su última edición sostiene que la desaparición del marxismo no debe llevar a los cristianos a confiar en el capitalismo como única alternativa social y económica, debido a las injusticias propias de este sistema, injusticias que él pudo considerar gracias a sus lecturas y postulados éticos derivados de sus estudios sobre Aristóteles y Tomás, principalmente.

También resulta esencial comprender su actividad académica, que lo llevó de estudiar Cultura Clásica en el Queen Mary College en la Universidad de Londres, escribiendo su tesis doctoral The significance of Moral Judgements en la Universidad de Manchester (Inglaterra) en 1951, a retirarse como profesor de Filosofía en la Duke University (Estados Unidos) en 1997. En esos más de cuarenta años de carrera, ejerció diferentes cargos y dictó diversas materias en Universidades de Gran Bretaña y Estados Unidos.

Como buen lector, primero del marxismo inglés, luego de Nietszche, Foucault y finalmente de los autores cristianos de los siglos XII y XIII, comprendió que la moral se constituye a partir de la historia y de las relaciones sociales establecidas en una comunidad determinada. Comunidad que si bien es social y política, resulta principalmente una comunidad que remite a sujetos, a hombres de encarnadura real que tienen conciencia, racionalidad y conocimientos como para elegir y actuar en cada momento determinado.

Es por ello que el autor construye y sustenta todo su andamiaje teórico y práctico en una antropología filosófica, la cual conjuga herencia y tradición con innovación y educación: una naturaleza humana heredada (o tal como es) pero que está destinada a ser una naturaleza perfeccionada (o tal como debería ser). MacIntyre denomina "florecimiento" al paso del primer al segundo estadio, florecimiento que resulta posible dentro de un contexto social en el que se ejerzan las virtudes intelectuales y morales.

Las virtudes intelectuales y morales son resultado tanto de la acción moral individual y comunitaria como de las tradiciones, entendidas como el fundamento de las costumbres sociales, que abarcan desde las prácticas más cotidianas hasta las investigaciones científicas.

En este contexto, destaca el estudio de la justicia, que es considerada como virtud, como bien y como justa generosidad. Además, la justicia ha sido un tema recurrente a lo largo de los escritos macinteryanos, siempre relacionada con otros temas importantes de su pensamiento: la política, la ética, el bien común, la antropología filosófica, las normas y las leyes con vistas a un fin superior, que es el más propio de una comunidad: la búsqueda de la felicidad humana y el logro del bien común.

Como propuesta esencial para su filosofía política, destaca a las comunidades locales, es decir las agrupaciones de personas con fines, normas e intereses comunes, que permiten las interrelaciones sociales a pequeña escala: escuelas, gremios, organizaciones de la sociedad civil, asociaciones vecinales, clubes, iglesias locales, universidades, entidades culturales y sociales, entendidas como 
formas accesibles de participación y discusión que tienen impacto político en la vida del Estado y la sociedad civil.

En momentos en que gran parte de la sociedad civil no reconoce valor en el ámbito político, Alasdair MacIntyre recupera dos sentidos muy distintos: por un lado, desde el punto de vista moderno, como una gran burocracia de partidos políticos en relación directa con el Estado; por el otro, la entiende en el sentido comunitarista, donde el aspecto institucional está ligado a lo social.

En este contexto, señala que el Estado moderno no resulta ser un árbitro neutral en los conflictos sociales, sino que, casi siempre, es parte activa en ellos y resulta ineficaz al momento de promover el bien común entre los miembros de un país. De allí la necesidad de la existencia y promoción de comunidades locales.

Fernández, profundo lector, conocedor e intérprete de la obra de MacIntyre, nos brinda un texto de referencia para todos aquellos interesados en este autor, dado que nos permite seguir histórica y teóricamente su desarrollo intelectual, las disputas filosóficas, y los planteos éticos y políticos generados a partir de sus postulados. 